ISBN 978-81-933894-1-6

International Conference on Arts, Social Sciences, History and Interdisciplinary Studies

(ASSHIS-2017)

Kyoto (Japan) April 20-21, 2017

\title{
Service Quality of True Shop, True Corporation Co., Ltd. (Public Company) Bangkok
}

\author{
Miss Panchita Phinimontree, Dr. Chinnaso Visitnitikija \\ Graduate School of Business Administration Kasembundit University, Bangkok
}

\begin{abstract}
The purpose of this study were to determine the factors affecting the service quality and satisfaction of service Center provided by True shop, True corporation Co., Ltd., (Public Company). The study of 400 respondents using the questionnaire as a tool to study. The statistics application used for data analysis were frequency, percentage, mean, standard deviation, $t$-test, and One-Way Anova.

The results from the study indicated that most of respondents were females, age between 21-35 years old, earned bachelor degree, work for private industries, average monthly income between 15,000-30,000 baht, and most of respondents paid for the service at True shop. The average picture of the opinions of factors affecting the service quality at service center provided by True Shop, True Corporation Co., Ltd., (Public Company) were at the high level consisting of caring, confidence, response to customer demand, credibility, and tangible. The average picture of the opinions of service satisfaction of the True Shop, True corporation Co., Ltd., (Public Company) were at the high level. The hypothesis testing revealed that the different of quality service provided and caring affected satisfaction of service Center provided by True shop, True corporation Co., Ltd., (Public Company) at significant level 0.05.

The recommendations from the study were to improve the quality of the service of the True Shop, True corporation Co., Ltd., (Public Company), to study on factors relating to quality of service in various areas to customer requirements, and to get the most accurate information based on users' feedback in order to bring information to improve the quality of the service of True Shop, True corporation Co., Ltd., (Public Company).
\end{abstract}

Keyword: service, quality

\section{Introduction}

Communications services are essential to the life of our people today. The telecommunications services. The competition is more intense And present Communications technology is advancing very rapidly. To accommodate the needs of service users. Until today, the world is becoming borderless world. This makes it important to communicate it becomes easy wireless technologies is $3 \mathrm{G}$ (3rd generation mobile telecommunications) and has developed as a 4G (4th Generation of Technology for Mobile Network).

$4 \mathrm{G}$ regarded as the era of the modern era for people around the world. Countries, we are moving into the era of the Thailand $4 \mathrm{G}$ by technology of high-speed wireless communications $4 \mathrm{G}$ or Long Term Evolution (LTE) technology is a technology that was developed to help reduce the limitations of data transmission GSM/GPRS/EDGE technology on the market today, added the ability to send and receive data with speeds up to $100 \mathrm{Mbps}$, and help to reduce delays in data transmission (Latency) (Office of the Board of management and the Northwestern national, 2556:1-53)

In the countries of Thailand, an 4G technology into use by true Corporation public company limited. When is the first camp May 82556 truemove h. 4G LTE (Long Term Evolution) technology is the latest development from 3G $+2100 \mathrm{MHz}$ frequency on for 3-5 times more 4G LTE network systems true Corporation, started in the $\mathrm{h}$ key points in the heart of Bangkok and expand the defence perimeter zone and served another 13 points in 15 provincial towns as well as an important business district, Bangkok shopping center. Supermarkets, convenience stores Flea market (4G provider network truemove h., 2557). 
The current competition's marketing network provider increased, both in regard to organize activities to attract service users of their network service. Which attract service users also use event marketing to attract customers and then. Another thing that can attract and retain their original customer base that is sensitive to "the service" of those financial statements and details of winning magazine warat (2555 (2012).)

Therefore, the mobile network operator. Need to develop and improve the services in accordance with customer's usage habits, meet the needs of our customers, and cause the maximum satisfaction

The service is key to the business. Providing network services for TrueMove $\mathrm{H}$ is one tool that can make a difference. And attract customers to the network operator TrueMove $\mathrm{H}$ in the long run also helps to build a good image and reputation of True Corporation Public Company Limited (), the other one with which the network TrueMove H. the need to develop and improve services strategy to date. And quality is always to meet customer demand. In each service should be facilitated. The quick service Each customer is accurate. Provide customer satisfaction of service received. And re-use the service again next time. He also established and maintained with the other one with meat laced finish Microbiology (2556).

If the provider can provide consistent service meets the needs and requirements of the service, or the service may create a higher level people expect. Will result in the birth of such services, quality of service, which will allow the customer satisfaction from the services received very seriously. Zeitaml, Berry and Parasuraman (1988), one important issue is the customer service is the result of a quality customer service was still not high enough level. As an organization, in spite of the expectation that the organization believed to have a try in every way to make customers aware of the quality, service and satisfaction. One of the reasons often occur from impaired organization, but the organization does not know what factors caused by the mind. "The sting", or awareness of customer service quality (saran yopnga, 2553 (2010))

From such a study, it is interesting to study the quality of call center services True Shop. True Corporation Public Company Limited (the Company) to be helpful in improving the service quality of service True Shop. True Corporation Public Company Limited () next.

\section{The Objectives of the Study}

To study the service quality of the true centre shopping company true Corp Corporation Limited (the company).To investigate the level of satisfaction with the service of the true centre shopping company Limited (the company).To study the factors influencing the quality of service satisfaction in the service of a center hole shopping Company Limited (public).

Scope of study.

The quality of the service, using the concept of safety be Parasuraman contains the reliability aspects of responding to the needs of the recipients of the services. Safety access to mind others boundaries, population, population in this study is that customers who use the services of service competitiveness centre. Select a sample number of 400 list The conceptual Theories, concepts, and theories about the quality of service.Parasuraman, and Berry (1985)

Study results Factors that affect the competitiveness of the Service Center provider. True Corporation PLC in the composition factors of 5 sides. Study results

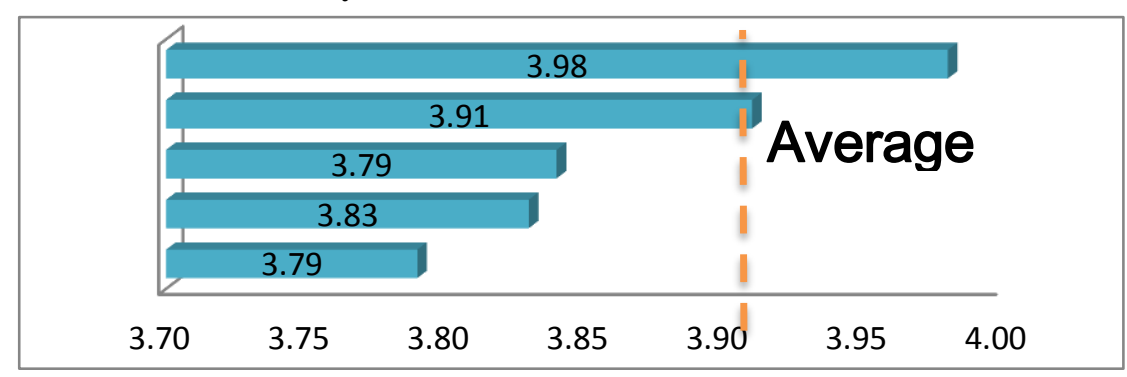

Fig. 1: Shows the factors that affect competitiveness outlets 
Data from the study found that factors that affect the quality of service competitiveness in the composition factors of 5 are 5 story on many levels-side descending order is the personal attention $(=3.98 \times \overline{)}$ confidence $(\mathrm{x}=$ $3.91 \overline{)}$ and are moderately 3 is typified by responding to needs $(x=3.79 \overline{)}$, credibility $(x=3.83)$. The concrete expertise $(\mathrm{x}=3.79 \overline{)}$ overall level of review of factors that affect the transport provider van icon in the composition factors (level 5 side $\mathrm{x}^{-}=3.85$.Information on customer satisfaction in the service shop True Shop. True Corporation Public Company Limited (Thailand).

Satisfaction in serving the competitiveness center.

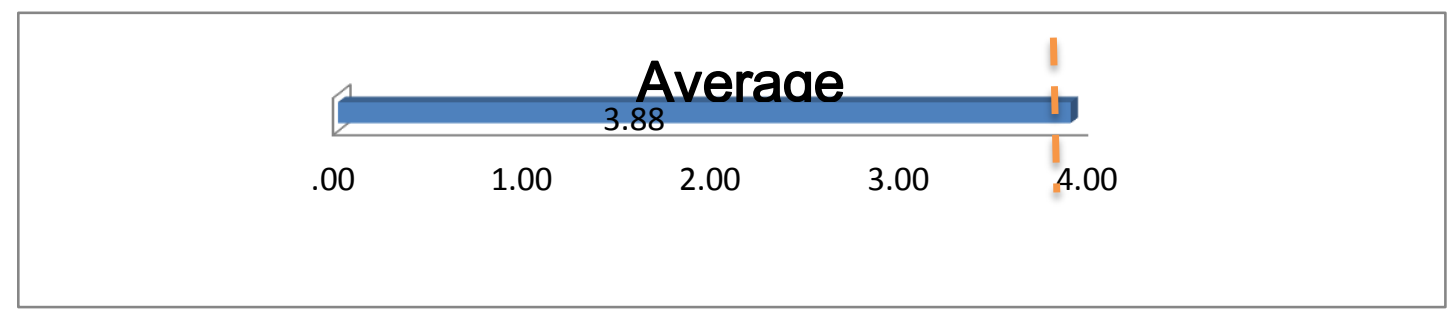

Fig. 2: Satisfaction of service overview.

The illustrations show the satisfaction of service.

The study found that overall satisfaction, service quality, service centers True Shop. True Corporation Public Company Limited (the Company) at a high level $\left(\mathrm{x}^{-}=3.88\right)$.

\section{Summary of Suggestions}

The study Quality of service centers True Shop. True Corporation Public Company Limited (Thailand) Ltd. aims to study the factors that affect the quality of services, service centers True Shop. And satisfaction in the service center for service. True Corporation Public Company Limited (Thailand) to improve the results of the study to optimize the center of True Shop. True Corporation Public Company Limited () method of the quantitative study. (Quantitative Research) study of 400 patients using a questionnaire as a tool in education. Statistics used were percentage, mean, standard deviation. To test the hypothesis t- test and One-Way ANOVA.

The factors of service quality, service centers True Shop. True Corporation Public Company Limited (Thailand) that influence the satisfaction of the customer. The findings of the study period. Dimensional quality of services delivered in 5 dimensions that influence the satisfaction of the customer. However, with restrictions And the potential of the study or the study of the barriers faced. The study could result in a partial answer.

Suggestions for further study for this study, the researcher collected data from a sample query, so for the next time. Students should find out more by quality of personnel at all levels to the results of the analysis of the quality of life is more comprehensive.

\section{References}

[1] Juljer julchai (1992) The development of the new employee orientation training kit for the expressway authority of Thailand. . Doctorate thesis. Bangkok: srinakharinwirot University

[2] Tosaporn mahamud (2011)“ Marketing Concept Planning” Kasembundit University,Bangkok

[3] Saranyapong tangtime ,2010 "Dynamic Diamond Model "Bangkok Univeraity

[4] Parasuraman, Zeithaml and Berry, "A Conceptual Model of Service Quality and Its Implications for Future Research," Journal of Marketing, Fall 1985, pp. 41-50.

[5] Varat vinit (2012). Principles of marketing. Chiang Mai: Marketing Department Business Administration, University of Chiang Mai. 